3 Resarerch Square

\title{
Noise-Induced Hearing Loss and Hypertension: A Preliminary Analysis of Baseline Data of Occupational Noise-Exposed Workers
}

\section{Long Miao}

Southeast University https://orcid.org/0000-0001-6949-5855

Lihong Yin

Southeast University

Yuepu Pu ( $\square$ yppu@seu.edu.cn )

Southeast University

\section{Research Article}

Keywords: Noise-induced hearing loss, Hypertension, Prevalence, Risk, Occupational noise

Posted Date: August 9th, 2021

DOI: https://doi.org/10.21203/rs.3.rs-699002/v1

License: (1) (i) This work is licensed under a Creative Commons Attribution 4.0 International License. Read Full License 


\section{Abstract}

The present study aimed to determine the current levels of systolic blood pressure (SBP), diastolic blood pressure (DBP) and binaural high frequency $(3,4$, and $6 \mathrm{kHz})$ threshold on average (BHFTA), to assess the prevalence of noise-induced hearing loss ( $\mathrm{NIHL}$ ) and hypertension and determine the factors influencing the risk of both, and to evaluate the association between $\mathrm{NIHL}$ and hypertension among occupational noise-exposed workers. Questionnaire and occupational health checkup were performed to collect the personal information and physical examination data. Finally, baseline data from 42,588 occupational noise-exposed workers were analyzed. The mean levels of SBP, DBP, and BHFTA were 126.85 $\pm 15.94 \mathrm{~mm} \mathrm{Hg}, 79.94 \pm 11.61 \mathrm{~mm} \mathrm{Hg}$ and $23.09 \pm 11.32 \mathrm{~dB}$, respectively. Of the 42,588 subjects, the prevalence of $\mathrm{NIHL}$ and hypertension were $24.38 \%(n=10,383)$ and $25.40 \%$ $(n=10,816)$. The results suggested that higher risk of $\mathrm{NIHL}$ and hypertension were more likely to be the groups of male gender, aged $>35$ years, exposure time to noise $>5$ years, and smoking. The SBP, DBP and BHFTA levels increased with age and noise exposure time $\left(P_{\text {trend }}<0.001\right)$. Besides, similar trends were also observed in the prevalence of NIHL and hypertension. Furthermore, there was a significant association of NIHL with hypertension. We found that $32.25 \%(n=3,348)$ workers with NIHL had hypertension. The mean levels of SBP and DBP in NIHL workers were significantly higher than those with normal hearing $(P<0.001)$. In addition, NIHL workers had a significantly higher risk of developing hypertension than normal hearing workers $($ adjusted $\mathrm{OR}=1.08,95 \% \mathrm{Cl}=$ 1.03-1.14). Our current findings suggest that the prevalence of NIHL and hypertension are high in our study workers and occupational noise exposure is an important factor. Therefore, it is urgent to reduce noise exposure in the workplaces and to strengthen industrial noise monitoring.

\section{Introduction}

Noise is a widespread occupational hazardous factor affecting the health of workers in occupational health field. To our knowledge, the most direct impact of noise is the damage to the auditory system, while the most serious health effect is irreversible noise-induced hearing loss (NIHL). NIHL is a progressive sensorineural hearing loss characterized by noise-induced auditory threshold shift at high-frequency. NIHL is a major occupational-related disease and is a severe occupational health problem in the workplace safety (Miao et al. 2019). It is worth noting that about ten percent of the world's population permanently are expose to high-intensity noise environment and are at risk of developing NIHL (Basner et al. 2014). Recently, with the rapid development of industry in China, noise is widespread in various industrial places, and a larger number of workers exposed to noise. Nowadays, NIHL has been the third largest occupational health hazard in China, the incidence of which has been increasing (Yu 2016). Recent studies have found that $16 \%$ of worldwide hearing loss in adults caused by occupational noise (Nelson et al. 2005). NIHL can cause communication disorder and result in social isolation, thus leading to self-abasement and cognitive decline and depression (Samelli et al. 2021). Therefore, it is an extreme important public health goal to prevent NIHL and reduce its adverse effects.

Except for adverse effects on auditory function, noise, as a psychosocial stressor, could induce biological effect on cardiovascular system and lead to hypertension (Ising \&Kruppa 2004; Sbihi et al. 2008). Previous studies suggested that the mechanism by which noise causes hypertension may be through activation of the hypothalamus-pituitary-adrenal gland and sympathetic nervous system, thus resulting in elevated levels of norepinephrine, epinephrine, and cortisol (Basner et al. 2014). Some studies have documented that workers exposed to occupational noise had a distinctly elevated blood pressure (Chang et al. 2003; Green et al. 1991) or had a higher risk of hypertension (Tomei et al. 2010; Zhao et al. 1991). It has reported that 9.4\% of cardiovascular 
disease (CVD) deaths are caused by hypertension (Lim et al. 2012). Hence, it is necessary to take early intervention for the prevention of noise-induced hypertension and its adverse effects.

Occupational noise as a prevalent occupational health risk may be present in many workplaces affecting workers' health and putting the workers' health at a high risk. In addition, considering the harmful effects of occupational noise on human health, we conducted this study to investigate the status of NIHL and hypertension, determine the potential risk factors, and evaluate the association between NIHL and hypertension by analyzing the baseline data from occupational health checkups of occupational noise-exposed workers.

\section{Materials And Methods Study subjects}

In this cross-sectional study, a total of 44,305 workers exposed to occupational noise who accepted occupational health checkups conducted from 2015 to 2017 by Yangzhou Center for Disease Control and Prevention. To avoid possible biases, a total of 1,717 workers who gave incomplete information of occupational noise exposure, did not accomplish the occupational health examinations, declined to participate, had a hereditary family history of deafness and a history of diagnosed hearing loss, otitis media, skull trauma, nervous tinnitus that could impair normal hearing, had a hereditary family history of cardiovascular diseases and hypertension, medical diagnosis history of hypertension, and previous or current use of drugs that could cause hearing loss and hypertension were excluded from this study. Finally, a total of 42,588 workers meeting the above inclusion criteria were recruited in this study. This study was reviewed and approved by the Ethics Committee of Zhongda Hospital, Affiliated Hospital of Southeast University before this study commenced. Informed consents were also obtained from each participant.

\section{Questionnaire survey}

A structured questionnaire was performed to collect information on demographic characteristics of all workers before occupational health checkups. The information included age, noise exposure time, hereditary history of deafness and hypertension, family history of cardiovascular diseases, smoking and drinking status, history of earrelated diseases (ear infections, head injury/trauma, and tinnitus), previous medical diagnosis of hypertension, and previous or current use of drugs was gathered. The information was used to screen participants for the current study. The Details of the definitions of smoking and drinking have been proposed elsewhere (Miao et al. 2021). In brief, workers had one cigarette per day for the at least one year were defined as smokers. Drinkers were defined as workers consumed a bottle of beer or fifty grams of wine per day for at least one year.

\section{Pure-tone audiometric examination and NIHL definition}

Pure-tone audiometric (PTA) examination was performed by a professional audiologist with a pure tone audiometer (Madsen Voyager 522, Taastrup, Denmark). All recruited workers underwent a PTA test after being away from the occupational noise exposure environment for at least fourteen hours or longer. According to the diagnostic criteria (GBZ 49-2014), hearing thresholds of left and right ears were assessed with the method of ascending pure tones at the frequencies of $0.5,1,2,3,4$, and $6 \mathrm{kHz}$. Furthermore, all hearing examinations were conducted in a soundproof room to ensure that the obtained results reflect the true levels of hearing thresholds of workers. In this study, workers whose binaural high frequency $(3,4$, and $6 \mathrm{kHz})$ threshold on average (BHFTA) greater than $25 \mathrm{~dB}$ were defined as $\mathrm{NIHL}$, while those less than $25 \mathrm{~dB}$ were defined as normal hearing. 


\section{Blood pressure measurement and hypertension}

Before blood collection and blood pressure measurement, all workers were asked to fast overnight. Blood pressure was evaluated by an experienced physician using an automated sphygmomanometer (TM-2655P, A\&D Corp., Japan) after workers sat for more than 10 minutes rest. The average value of three repeated blood pressure measurements with 30 seconds interval was applied to reflect the true level of an individual's blood pressure. Workers who had mean resting systolic blood pressure (SBP) $\geq 140 \mathrm{~mm} \mathrm{Hg}$ and/or mean resting diastolic blood pressure $(\mathrm{DBP}) \geq 90 \mathrm{~mm} \mathrm{Hg}$ were defined as hypertensive.

\section{Statistical analysis}

Descriptive statistics were computed as mean, standard deviation (SD) and frequency percentages. Shapiro-Wilk test was used to determine the normality of continuous variables including SBP, DBP, and binaural high frequency hearing threshold. Student's $t$ test and Kruskal-Wallis test were applied to determine the significance differences of continuous variables. Two-side $\chi^{2}$ test was applied to examine statistical differences in frequency distribution of category variables. For the significantly different group, the Mann-Whitney test and $\chi^{2}$ test were used to compare the statistical significance of variables among groups. In addition, multivariate logistic regression, calculated odds ratios (ORs) and 95\% confidence intervals (Cls) to assess the strength of association between selected variables and NIHL and hypertension by controlling potential confounding factors, such as age, gender, noise exposure time, smoking and drinking status. The SPSS version 23.0 (SPSS, Chicago, Illinois, USA) for Mac was performed for all statistical analyses. The statistical significance was set as $P$ values $<0.05$.

\section{Results}

\section{Characteristics of study subjects}

Table 1 summarizes the demographic characteristics of this cross-sectional study comprised 42,588 subjects who exposed to occupational noise. Among the recruited subjects, $74.76 \%$ were male $(n=31,838)$, and $25.24 \%$ were female $(n=10,750)$. The mean age was $36.58 \pm 9.56$ years, with $44.30 \%$ of workers were at the age of $18-34$ years, $31.38 \%$ were $35-44$ years, and $24.33 \%$ were older than 45 years. The mean exposure time to noise was $9.20 \pm 8.38$ years, with $38.57 \%$ of workers were exposed to noise for less than 5 years, $30.03 \%$ were in the range of $5-10$ years, and $31.40 \%$ had a noise exposure history of greater than 10 years. Furthermore, in all subjects, $33.44 \%$ and $33.52 \%$ were smokers and drinkers.

\section{Prevalence of NIHL and hypertension}

As shown in Fig. 1, the mean levels of SBP, DBP and BHFTA were $126.85 \pm 15.94 \mathrm{~mm} \mathrm{Hg}, 79.94 \pm 11.61 \mathrm{~mm} \mathrm{Hg}$ and $23.09 \pm 11.32 \mathrm{~dB}$, respectively. Meanwhile, among the included 42,588 subjects, the prevalence of NIHL and hypertension were $24.38 \%(n=10,383)$ and $25.40 \%(n=10,816)$.

\section{Stratified analysis of the levels of SBP and DBP and prevalence of hypertension}

Table 2 shows the stratified analysis results of SBP and DBP levels and prevalence of hypertension by study groups. There was a significant difference in the levels of SBP and DBP, and the prevalence of hypertension between different gender, age, noise exposure time, smoking and drinking groups $(P<0.001)$. The male, smoking and drinking workers had significantly higher levels of SBP and DBP, and prevalence rates of hypertension than the 
female, non-smoking and non-drinking workers. Besides, we found that a similar result revealing that males and smokers were at significantly higher risk for hypertension (adjusted OR $=2.19,95 \% \mathrm{Cl}=2.05-2.34$; adjusted OR = $1.11,95 \% \mathrm{Cl}=1.05-1.17$, respectively). There was a statistical significance in the SBP and DBP levels among the groups with different age and noise exposure time, and both SBP and DBP levels increased with the gradual increase of age and noise exposure time $\left(P_{\text {trend }}<0.001\right)$. The multivariate logistic regression analysis showed that age and noise exposure time were significantly associated with hypertension even after adjusting for potential confounders. The subgroups of age 35-44 and > 44 years had a 2.33-fold and 3.82-fold greater OR for hypertension than age less than 35 years. A similar result in the subgroups of noise exposure time 5-10 and > 10 years was also found.

\section{Stratified analysis of binaural high frequency threshold on average and prevalence of NIHL}

As shown in Table 3, we found that workers in the subgroups of male gender, smoking and drinking had a significantly higher BHFTA compared with female, non-smoking and non-drinking workers $(P<0.001)$. Totally, 8,162 males, 4,289 smokers and 3,715 drinkers out of all the recruited subjects were diagnosed as having $\mathrm{NIHL}$, with the prevalence of $25.64 \%, 30.12 \%$ and $26.02 \%$, significantly higher than female $(20.66 \%)$, non-smoking (21.50\%) and non-drinking (23.55\%) Male and smoking workers had a significantly higher risk of NIHL (adjusted

$\mathrm{OR}=1.52,95 \% \mathrm{Cl}=1.42-1.62 ;$ adjusted $\mathrm{OR}=1.09,95 \% \mathrm{Cl}=1.03-1.16)$. Besides, there was a significant difference in the level of BHFTA between the three subgroups of age and noise exposure time $(P<0.001)$, and significantly elevated with the cumulative of age and noise exposure time. Correspondingly, workers aged $35-44(27.44 \%, P<$ $0.001)$ and $>44(39.79 \% \%, P<0.001)$ with BHFTA of $23.86 \pm 11.45 \mathrm{~dB}$ and $26.47 \pm 14.72 \mathrm{~dB}$ had significantly higher prevalence rates of $\mathrm{NIHL}$ than workers younger than 35 years (13.75\%). Workers who exposed to noise time $5-10$ years $(30.73 \% \%, P<0.001)$ and $>10$ years $(35.15 \% \%, P<0.001)$ with BHFTA of $24.30 \pm 12.06 \mathrm{~dB}$ and $25.16 \pm$ $13.51 \mathrm{~dB}$ had significantly higher prevalence rates of NIHL than noise exposure less than 5 years workers (10.67\%). Similar results also could be observed in the risk of NIHL, which indicated that the risk of NIHL in the subgroups of age between 35 and 44 (adjusted $\mathrm{OR}=1.93,95 \% \mathrm{Cl}=1.81-2.05$ ) and $>44$ years (adjusted $\mathrm{OR}=3.16,95 \% \mathrm{Cl}=2.96$ 3.38), noise exposure time $5-10$ years (adjusted $\mathrm{OR}=3.35,95 \% \mathrm{Cl}=3.14-3.57$ ) and $>10$ years (adjusted $\mathrm{OR}=2.72$, $95 \% \mathrm{Cl}=2.54-2.91)$ was significantly higher compared to aged $<35$ years and noise exposure time $<5$ years $(P<$ $0.001)$.

\section{Analysis of association between NIHL and hypertension}

To determine the association between NIHL and hypertension, the subjects were divided into normal hearing and $\mathrm{NIHL}$ groups. The results showed that the mean levels of SBP $(130.03 \pm 16.89 \mathrm{~mm} \mathrm{Hg})$ and DBP $(82.16 \pm 12.21$ $\mathrm{mm} \mathrm{Hg})$ in 10,383 NIHL workers were significantly higher than those with normal hearing $(125.82 \pm 15.48 \mathrm{~mm} \mathrm{Hg}$ for SBP and $79.23 \pm 11.32 \mathrm{~mm} \mathrm{Hg}$ for DBP) $(P<0.001)$. The prevalence of hypertension in normal hearing group was $23.19 \%$, while $32.25 \%$ in NIHL group, and a statistically significant difference was found between the two groups $(P<0.001)$. Furthermore, compared with normal hearing workers, NIHL workers had 1.08 times higher risk of hypertension after correcting confounding factors (adjusted OR $=1.08,95 \% \mathrm{Cl}=1.03-1.14$ ) $($ Table 4).

\section{Discussion}

Based on the data from occupational health checkups of 42,588 occupational noise-exposed workers, we investigated the levels of SBP, DBP and BHFTA, prevalence of NIHL and hypertension. Besides, we evaluated the association between $\mathrm{NIHL}$ and hypertension. Among the included 42,588 subjects, we found that the prevalence of 
hypertension and $\mathrm{NIHL}$ were $25.40 \%$ and $24.38 \%$. We also found that the prevalence rates of NIHL and hypertension were significantly higher in subgroups of male gender, aged 35-44 and >44 years, noise exposure time 5-10 and > 10 years, and smoking workers. Higher risks of NIHL and hypertension were also occurred in the above study groups. In addition, there was a significant difference between NIHL and hypertension; the risk of hypertension in NIHL group was 1.08-fold greater than in normal hearing group.

Generally, noise is considered as a set of sounds that could make people irritable or is loud enough to endanger everybody. In environment, there are diverse sources of noise, including transportation noise, occupational noise, and construction noise. Nowadays, noise pollution has been an important and neglected public health issue in the world. Adverse health effects of noise on human beings can be observed on psychologically and physiologically (Muzet 2007). The WHO reported that mental, behavioral, and neurological diseases affected by noise account for $3 \%$ of global deaths and $10 \%$ of global burden of disease (Minichilli et al. 2018). Recent evidence showed that long-term exposure to environmental noise could cause some adverse health effects, such as sleep disturbance (Halperin 2014), annoyance (Minichilli et al. 2018), learning impairment (Erickson \&Newman 2017), and hypertension (Dratva et al. 2012).

Occupational noise, a common harmful factor that seriously affects health of workers in the field of occupational health. Noise-induced hearing loss ( $\mathrm{NIHL})$ is one of the worst adverse health effects induced by occupational noise exposure in workplaces (Masterson et al. 2016). The WHO reported that about $10 \%$ of the world's population is exposed to high level of noise and at risk of progressing to NIHL (Basner et al. 2014). A recent review revealed that occupational noise exposure resulted in $7-21 \%$ of workers' hearing loss, with the lowest incidence in industrialized countries and the highest in developing countries (Lie et al. 2016). According to previous study, NIHL is one of the leading occupational related disease in China, accounting for approximately one-sixth of the annual increase of occupational disease (Yu 2016). Many epidemiological investigations showed that high frequency hearing loss is mainly caused by occupational noise exposure (Alabdulwahhab et al. 2016; Maccà et al. 2015). In this study, the prevalence of NIHL was $24.38 \%$, which was higher than the results from previous research conducted by Lie A et al. (2016) showing that approximately 7 to $21 \%$ of $\mathrm{NIHL}$ caused by occupational noise exposure. Thus, we could conclude that NIHL has become an urgent occupational health problem that damages workers' health in China. Nelson DI et al. (2005) reported that the harmful effects of occupational noise exposure on NIHL were larger among males than females, which was consistent with our current study. It has been shown that a key factor contributing to $\mathrm{NIHL}$ is oxidative stress damage to sensory hair cells (Yuan et al. 2015). In the present study, a significantly higher risk of NIHL was observed in workers aged $>35$ years, and noise exposure time $>5$ years, with adjusted ORs gradually increasing with increasing of age and noise exposure, which was corroborated from previous studies (Hormozi et al. 2017). Meanwhile, it should be worth noting that aging and duration with noise were the most common cause of $\mathrm{NIHL}$, and both closely related to the formation of reactive oxygen species, which was the major product of oxidative stress (Li et al. 2019). Smoking was found to be associated with an increased risk for hearing loss (Hu et al. 2019; Tao et al. 2013). Wang D et al. (2017) also found that smoking is an independent risk factor for NIHL, and it may have a dose-response relationship on NIHL. However, the specific pathogenic mechanisms underlying smoking increases the risk of hearing loss is not well understood. Studies have suggested that smoking may damage cochlea hair cells via increasing carboxyhemoglobin or reducing cochlear blood flow to the cochlea (Palmer et al. 2004). A previous study found that no significant association between drinking and the risk of NIHL (Itoh et al. 2001), which showed the same results as our study.

It has been reported that persons with chronic and repeated exposure to noise appeared a persistent increased of blood pressure or a higher risk of hypertension (Dzhambov \&Dimitrova 2018; Liu et al. 2016). In this study, 
altogether, $25.40 \%$ of the workers included in our study had hypertension, suggesting a higher incidence of this disease. Workers particularly in the subgroups of male gender, aged $>35$ years, exposure time with noise $>5$ years, and smoking were more likely to develop hypertension, which in accordance with observed trends in previous studies (Evrard et al. 2017; Li et al. 2019; Samelli et al. 2021; Talukder et al. 2011). We concluded that workers with the above characteristics were high risk individuals of developing hypertension in occupational noise settings. According to recent reports showed that the consequence of hypertension caused by noise exposure might be attributed to stress response, thereby resulting in the elevated level of stress hormones such as catecholamine (Ghotbi et al. 2013; van Kempen et al. 2002). Moreover, a study on the effects of environmental noise exposure on CVDs has revealed that catecholamine could raise myocardial contractibility and enhance the output of blood pressure and cardiac by regulating $\beta-1$ receptors (Münzel et al. 2014). Yet other related studies have not found any significant correlation (Gan \&Mannino 2018; Stokholm et al. 2013; Zamanian et al. 2013). Hence, there is still a lack of consensus on this issue. It is remarkable that the differences of results observed in different studies may be influenced by the population studied and auditory sensitivity. Therefore, further studies in more detail are needed to precisely determine the mechanism underlying this inconsistent.

To explore the association between NIHL and hypertension, we divided the workers into normal hearing group and NIHL group according to the level of BHFTA. The current study suggested that NIHL workers had a significantly higher level of SBP and DBP compared to those in normal hearing group. Similarly, a study $(n=618)$ performed by $\mathrm{Ni} \mathrm{CH}$ et al. revealed that the mean levels of SBP and DBP in the NIHL group were significantly higher than those in the normal hearing group (Ni et al. 2007). Meanwhile, the findings of our study suggested that the prevalence rate of hypertension in NIHL differed from that in normal hearing workers by $9.1 \%$; the risk of developing hypertension in NIHL workers was 1.08 times that of normal hearing workers. Kuang D et al. (2019) investigated the association of high-frequency hearing loss and hypertension among occupational noise exposed workers and indicated that workers with mild high-frequency hearing loss (hearing level $>25$ but $<40 \mathrm{~dB}$ ) had a higher hypertension risk of $34 \%$. Also, the findings of another research involving 119 workers indicated that high frequency hearing loss was significantly associated with hypertension (Tarter \&Robins 1990). Moreover, a cross-sectional study included 790 male aircraft-manufacturing individuals had reported that workers with high frequency hearing loss (4 and $6 \mathrm{kHz})$ had higher risk of hypertension (Chang et al. 2011). Our current findings were consistent with the above-described findings regarding NIHL association with higher levels of SBP and DBP, as well as hypertension risk. Therefore, our study provided evidence that NIHL was associated with the risk of hypertension and it may act a potential biomarker of noise-induced hypertension for occupational noise-exposed workers.

\section{Strengths And Limitations}

Our present study is a cross-sectional study based on the data from occupational health checkups of 42,588 occupational noise-exposed workers. Strengths of the study are large sample size and high response rate among the subjects, as well as the occupational health checkups performed by certified and experienced physician and audiologists, thus ensuring the accuracy and credibility of all data; findings obtained based on this large sample size is more convincing. Besides, subgroup analysis of variables was conducted to avoid potential confounding factors. However, several limitations are also present in the current study and need to be mentioned. First, this study was based on a cross-sectional analysis, the results should be verified by prospective cohort studies in the future. Second, the questionnaire survey based on self-report measures of participants, which may cause bias to the results of the study. Third, some data and information were not collected, including levels of noise exposure in the workplaces, hearing protection measure, the usage of headphones, BMI, which were crucial factors influencing 
hearing loss and hypertension. Hence, in future studies, we will pay more attention to collecting the above missing data to make the results more convincing.

\section{Prevention Recommendations On Noise Health Hazards}

It can conclude that the prevalence rates of NIHL and hypertension are high in our study workers and occupational noise exposure is an important factor. We suggest that reducing noise exposure in the workplaces and improving preventive measure to prevent occupational noise-exposed workers from NIHL, hypertension, and other adverse health effects. In addition, occupational noise-exposed workers should strengthen own protection consciousness and wear earplugs properly while working.

Regular PTA examination and blood pressure monitoring should be performed by physicians among occupational noise-exposed workers. Also, safety standards for noise in the workplaces should also be monitored regularly to decide if compliance with the safety standards of industrial noise. Finally, if workers were identified to have potential risk of developing NIHL and hypertension by screening should be transferred to new job post with less or no noise exposure.

\section{Conclusions}

In this study, based on the data of occupational health checkups from 42,588 occupational noise-exposed workers, we can draw the following conclusions: (1) a large number of workers exposed to occupational noise, and the mean noise exposure time was $>9.20$ years; (2) the prevalence rates of NIHL and hypertension were $24.38 \%$ and $25.40 \%$, respectively; (3) the prevalence of NIHL and hypertension increased with age and noise exposure time; (4) significantly higher risk of $\mathrm{NIHL}$ and hypertension was observed especially in the group of male gender, aged $>35$ years, noise exposure time > 5 years, and smoking; (5) finally, of all the study participants, $32.25 \%$ workers with NIHL had hypertension. NIHL workers were at higher risk of developing hypertension than that of normal hearing workers.

The findings of this study suggest that occupational noise is an important occupational health risk affecting workers' health and putting the workers' health at a high risk. Hence, it is urgent to reduce noise exposure among workers in workplaces by performing regularly industrial noise monitoring and health risk evaluation, strengthening the implementation of safety standards of industrial noise, and raising workers' awareness of wearing earplugs properly, and carrying out high-risk population screening.

\section{Declarations}

\section{Acknowledgments}

The authors thank every worker for their participations in this study.

\section{Authors' contributions}

YP designed the research study. LM performed the research and analyzed the data. LM drafted the manuscript. LY critically reviewed and revised the manuscript. All authors read and approved the final manuscript.

\section{Funding}


This study was supported by the Open Research Fund of State Key Laboratory of Bioelectronics, Southeast University.

\section{Data availability}

The datasets used and analyzed during the current study are available from the corresponding author on reasonable request.

\section{Compliance with ethical standards}

\section{Conflict of interest}

The authors declare that they have no conflicts of interest.

\section{Ethical approval}

The present study was approved by the Ethics Committee of Zhongda Hospital, Affiliated Hospital of Southeast University.

\section{Consent to participate}

Informed consent was obtained from all individual participants included in the study.

\section{Consent to publish}

The participant has consented to the submission of the case report to the journal.

\section{References}

1. Alabdulwahhab BM, Alduraiby RI, Ahmed MA, Albatli LI, Alhumain MS, Softah NA, Saleh S (2016) Hearing loss and its association with occupational noise exposure among Saudi dentists: a cross-sectional study. BDJ Open 2:16006

2. Basner M, Babisch W, Davis A, Brink M, Clark C, Janssen S, Stansfeld S (2014) Auditory and non-auditory effects of noise on health. Lancet 383:1325-1332

3. Chang TY, Jain RM, Wang CS, Chan CC (2003) Effects of occupational noise exposure on blood pressure. J Occup Environ Med 45:1289-1296

4. Chang TY, Liu CS, Huang KH, Chen RY, Lai JS, Bao BY (2011) High-frequency hearing loss, occupational noise exposure and hypertension: a cross-sectional study in male workers. Environ Health 10:35

5. Dratva J, Phuleria HC, Foraster M, Gaspoz JM, Keidel D, Künzli N, Liu LJ, Pons M, Zemp E, Gerbase MW, Schindler C (2012) Transportation noise and blood pressure in a population-based sample of adults. Environ Health Perspect 120:50-55

6. Dzhambov AM, Dimitrova DD (2018) Residential road traffic noise as a risk factor for hypertension in adults: Systematic review and meta-analysis of analytic studies published in the period 2011-2017. Environ Pollut 240:306-318

7. Erickson LC, Newman RS (2017) Influences of background noise on infants and children. Curr Dir Psychol Sci 26:451-457 
8. Evrard AS, Lefèvre M, Champelovier P, Lambert J, Laumon B (2017) Does aircraft noise exposure increase the risk of hypertension in the population living near airports in France? Occup Environ Med 74:123-129

9. Gan WQ, Mannino DM (2018) Occupational Noise Exposure, Bilateral High-Frequency Hearing Loss, and Blood Pressure. J Occup Environ Med 60:462-468

10. Ghotbi MR, Khanjani N, Barkhordari A, Rahimi Moghadam S, Mozaffari A, Gozashti MH (2013) Changes in urinary catecholamines in response to noise exposure in workers at Sarcheshmeh Copper Complex, Kerman, Iran. Environ Monit Assess 185:8809-8814

11. Green MS, Schwartz K, Harari G, Najenson T (1991) Industrial noise exposure and ambulatory blood pressure and heart rate. J Occup Med 33:879-883

12. Halperin D (2014) Environmental noise and sleep disturbances: A threat to health? Sleep Sci 7:209-212

13. Hormozi M, Ansari-Moghaddam A, Mirzaei R, Dehghan Haghighi J, Eftekharian F (2017) The risk of hearing loss associated with occupational exposure to organic solvents mixture with and without concurrent noise exposure: A systematic review and meta-analysis. Int J Occup Med Environ Health 30:521-535

14. Hu H et al. (2019) Smoking, Smoking Cessation, and the Risk of Hearing Loss: Japan Epidemiology Collaboration on Occupational Health Study. Nicotine Tob Res 21:481-488

15. Ising H, Kruppa B (2004) Health effects caused by noise: evidence in the literature from the past 25 years. Noise Health 6:5-13

16. Itoh A, Nakashima T, Arao H, Wakai K, Tamakoshi A, Kawamura T, Ohno Y (2001) Smoking and drinking habits as risk factors for hearing loss in the elderly: epidemiological study of subjects undergoing routine health checks in Aichi, Japan. Public Health 115:192-196

17. Kuang D, Yu YY, Tu C (2019) Bilateral high-frequency hearing loss is associated with elevated blood pressure and increased hypertension risk in occupational noise exposed workers. PLoS One 14:e0222135

18. Li X, Dong Q, Wang B, Song H, Wang S, Zhu B (2019) The Influence of Occupational Noise Exposure on Cardiovascular and Hearing Conditions among Industrial Workers. Sci Rep 9: 11524

19. Lie A, Skogstad M, Johannessen HA, Tynes T, Mehlum IS, Nordby KC, Engdahl B, Tambs K (2016) Occupational noise exposure and hearing: a systematic review. Int Arch Occup Environ Health 89:351-372

20. Lim SS et al. (2012) A comparative risk assessment of burden of disease and injury attributable to 67 risk factors and risk factor clusters in 21 regions, 1990-2010: a systematic analysis for the Global Burden of Disease Study 2010. Lancet 380:2224-2260

21. Liu J, Xu M, Ding L, Zhang H, Pan L, Liu Q, Ding E, Zhao Q, Wang B, Han L, Yang D, Zhu B (2016) Prevalence of hypertension and noise-induced hearing loss in Chinese coal miners. J Thorac Dis 8:422-429

22. Maccà I, Scapellato ML, Carrieri M, Maso S, Trevisan A, Bartolucci GB (2015) High-frequency hearing thresholds: effects of age, occupational ultrasound and noise exposure. Int Arch Occup Environ Health 88:197211

23. Masterson EA, Bushnell PT, Themann CL, Morata TC (2016) Hearing Impairment Among Noise-Exposed Workers - United States, 2003-2012. MMWR Morb Mortal Wkly Rep 65:389-394

24. Miao L, Ji J, Wan L, Zhang J, Yin L, Pu Y (2019) An overview of research trends and genetic polymorphisms for noise-induced hearing loss from 2009 to 2018. Environ Sci Pollut Res Int 26:34754-34774

25. Miao L, Wang B, Zhang J, Yin L, Pu Y (2021) A functional SNP in miR-625-5p binding site of AKT2 3'UTR is associated with noise-induced hearing loss susceptibility in the Chinese population. Environ Sci Pollut Res Int 
26. Minichilli F, Gorini F, Ascari E, Bianchi F, Coi A, Fredianelli L, Licitra G, Manzoli F, Mezzasalma L, Cori L (2018) Annoyance Judgment and Measurements of Environmental Noise: A Focus on Italian Secondary Schools. Int J Environ Res Public Health 15

27. Münzel T, Gori T, Babisch W, Basner M (2014) Cardiovascular effects of environmental noise exposure. Eur Heart J 35:829-836

28. Muzet A (2007) Environmental noise, sleep and health. Sleep Med Rev 11:135-142

29. Nelson DI, Nelson RY, Concha-Barrientos M, Fingerhut M (2005) The global burden of occupational noiseinduced hearing loss. Am J Ind Med 48:446-458

30. Ni CH, Chen ZY, Zhou Y, Zhou JW, Pan JJ, Liu N, Wang J, Liang CK, Zhang ZZ, Zhang YJ (2007) Associations of blood pressure and arterial compliance with occupational noise exposure in female workers of textile mill. Chin Med J (Engl) 120:1309-1313

31. Palmer KT, Griffin MJ, Syddall HE, Coggon D (2004) Cigarette smoking, occupational exposure to noise, and self reported hearing difficulties. Occup Environ Med 61:340-344

32. Samelli AG, Santos IS, Padilha F, Gomes RF, Moreira RR, Rabelo CM, Matas CG, Bensenor IM, Lotufo PA (2021) Hearing loss, tinnitus, and hypertension: analysis of the baseline data from the Brazilian Longitudinal Study of Adult Health (ELSA-Brasil). Clinics (Sao Paulo) 76:e2370

33. Sbihi H, Davies HW, Demers PA (2008) Hypertension in noise-exposed sawmill workers: a cohort study. Occup Environ Med 65:643-646

34. Stokholm ZA, Bonde JP, Christensen KL, Hansen AM, Kolstad HA (2013) Occupational noise exposure and the risk of hypertension. Epidemiology 24:135-142

35. Talukder MA, Johnson WM, Varadharaj S, Lian J, Kearns PN, El-Mahdy MA, Liu X, Zweier JL (2011) Chronic cigarette smoking causes hypertension, increased oxidative stress, impaired NO bioavailability, endothelial dysfunction, and cardiac remodeling in mice. Am J Physiol Heart Circ Physiol 300:H388-396

36. Tao L, Davis R, Heyer N, Yang Q, Qiu W, Zhu L, Li N, Zhang H, Zeng L, Zhao Y (2013) Effect of cigarette smoking on noise-induced hearing loss in workers exposed to occupational noise in China. Noise Health 15:67-72

37. Tarter SK, Robins TG (1990) Chronic noise exposure, high-frequency hearing loss, and hypertension among automotive assembly workers. J Occup Med 32:685-689

38. Tomei G, Fioravanti M, Cerratti D, Sancini A, Tomao E, Rosati MV, Vacca D, Palitti T, Di Famiani M, Giubilati R, De Sio S, Tomei F (2010) Occupational exposure to noise and the cardiovascular system: a meta-analysis. Sci Total Environ 408:681-689

39. van Kempen EE, Kruize H, Boshuizen HC, Ameling CB, Staatsen BA, de Hollander AE (2002) The association between noise exposure and blood pressure and ischemic heart disease: a meta-analysis. Environ Health Perspect 110:307-317

40. Wang D, Wang Z, Zhou M, Li W, He M, Zhang X, Guo H, Yuan J, Zhan Y, Zhang K, Zhou T, Kong W, Chen W (2017) The combined effect of cigarette smoking and occupational noise exposure on hearing loss: evidence from the Dongfeng-Tongji Cohort Study. Sci Rep 7:11142

41. Yu SF (2016) [Strengthen the research for the prevention and control of occupational noise-induced hearing loss in our country]. Zhonghua Lao Dong Wei Sheng Zhi Ye Bing Za Zhi 34:881-883

42. Yuan H, Wang X, Hill K, Chen J, Lemasters J, Yang SM, Sha SH (2015) Autophagy attenuates noise-induced hearing loss by reducing oxidative stress. Antioxid Redox Signal 22:1308-1324 
43. Zamanian Z, Rostami R, Hasanzadeh J, Hashemi H (2013) Investigation of the effect of occupational noise exposure on blood pressure and heart rate of steel industry workers. J Environ Public Health 2013:256060

44. Zhao YM, Zhang SZ, Selvin S, Spear RC (1991) A dose response relation for noise induced hypertension. Br J Ind Med 48:179-184

\section{Tables}

Table 1 Demographic characteristics of 42,588 occupational noise exposure workers

\begin{tabular}{|c|c|c|c|}
\hline Characteristics & Mean \pm SD & Frequency & Percentage \\
\hline \multicolumn{4}{|l|}{ Gender } \\
\hline Female & & 10750 & 25.24 \\
\hline Male & & 31838 & 74.76 \\
\hline Age (years) & $36.58 \pm 9.56$ & & \\
\hline $18-34$ & & 18865 & 44.30 \\
\hline $35-44$ & & 13363 & 31.38 \\
\hline$\geq 45$ & & 10360 & 24.33 \\
\hline Noise exposure time (years) & $9.20 \pm 8.38$ & & \\
\hline$<5$ & & 16425 & 38.57 \\
\hline $5-10$ & & 12790 & 30.03 \\
\hline$>10$ & & 13373 & 31.40 \\
\hline \multicolumn{4}{|l|}{ Smoking status } \\
\hline No & & 28346 & 66.56 \\
\hline Yes & & 14242 & 33.44 \\
\hline \multicolumn{4}{|l|}{ Drinking status } \\
\hline No & & 28311 & 66.48 \\
\hline Yes & & 14277 & 33.52 \\
\hline
\end{tabular}


Table 2 Stratified analysis of the levels of SBP and DBP and prevalence of hypertension by different variable groups

\begin{tabular}{|c|c|c|c|c|c|c|c|c|c|}
\hline \multirow[t]{2}{*}{ Variable } & \multirow[t]{2}{*}{$\mathrm{n}$} & $\begin{array}{l}\text { Resting } \\
\text { SBP }\end{array}$ & \multirow[t]{2}{*}{$P$} & $\begin{array}{l}\text { Resting } \\
\text { DBP }\end{array}$ & \multirow[t]{2}{*}{$P$} & \multicolumn{2}{|c|}{ Hypertension } & \multirow[t]{2}{*}{$p^{e}$} & \multirow{2}{*}{$\begin{array}{l}\text { Adjusted } \\
\text { OR }(95 \% \\
\text { Cl) }\end{array}$} \\
\hline & & $\begin{array}{l}\text { Mean } \pm \\
\text { SD }(m m \\
\mathrm{Hg})\end{array}$ & & $\begin{array}{l}\text { Mean } \pm \\
\text { SD }(m m \\
\mathrm{Hq})\end{array}$ & & $\mathrm{n}$ & $\%$ & & \\
\hline
\end{tabular}

Gender

\begin{tabular}{|c|c|c|c|c|c|c|c|c|c|}
\hline Female & 10750 & $\begin{array}{l}122.53 \pm \\
15.91\end{array}$ & $\begin{array}{l}< \\
0.001^{a}\end{array}$ & $\begin{array}{l}76.64 \pm \\
10.90\end{array}$ & $\begin{array}{l}< \\
0.001^{a}\end{array}$ & 1808 & 16.82 & $\begin{array}{l}< \\
0.001\end{array}$ & $\begin{array}{l}1.00 \\
\text { (ref) }\end{array}$ \\
\hline Male & 31838 & $\begin{array}{l}128.31 \pm \\
15.68\end{array}$ & & $\begin{array}{l}81.06 \pm \\
11.64\end{array}$ & & 9008 & 28.29 & & $\begin{array}{l}2.19 \\
(2.05- \\
2.34)\end{array}$ \\
\hline
\end{tabular}

Age (years)

\begin{tabular}{|c|c|c|c|c|c|c|c|c|c|}
\hline$<35$ & 18865 & $\begin{array}{l}123.28 \pm \\
13.88\end{array}$ & $\begin{array}{l}< \\
0.001^{b}\end{array}$ & $\begin{array}{l}76.85 \pm \\
10.37\end{array}$ & $\begin{array}{l}<.001^{b} \\
\end{array}$ & 2832 & 15.01 & & $\begin{array}{l}1.00 \\
\text { (ref) }\end{array}$ \\
\hline $35-44$ & 13363 & $\begin{array}{l}127.32 \pm \\
16.01^{c}\end{array}$ & & $\begin{array}{l}80.86 \pm \\
11.83 c\end{array}$ & & 3739 & 27.98 & $\begin{array}{l}< \\
0.001\end{array}$ & $\begin{array}{l}2.33 \\
(2.19- \\
2.48)\end{array}$ \\
\hline$>44$ & 10360 & $\begin{array}{l}132.74 \pm \\
17.45^{\mathrm{cd}}\end{array}$ & & $\begin{array}{l}84.38 \pm \\
11.83 \mathrm{~cd}\end{array}$ & & 4245 & 40.97 & $\begin{array}{l}< \\
0.001\end{array}$ & $\begin{array}{l}3.82 \\
(3.58- \\
4.08)\end{array}$ \\
\hline
\end{tabular}

Noise

exposure time

(years)

\begin{tabular}{|c|c|c|c|c|c|c|c|c|c|}
\hline$<5$ & 16425 & $\begin{array}{l}124.52 \pm \\
14.89\end{array}$ & $\begin{array}{l}< \\
0.001^{b}\end{array}$ & $\begin{array}{l}77.98 \pm \\
10.92\end{array}$ & $\begin{array}{l}< \\
0.001^{b}\end{array}$ & 3124 & 19.02 & & $\begin{array}{l}1.00 \\
\text { (ref) }\end{array}$ \\
\hline $5-10$ & 12790 & $\begin{array}{l}126.70 \pm \\
15.95^{c}\end{array}$ & & $\begin{array}{l}79.63 \pm \\
11.65 c\end{array}$ & & 3077 & 24.06 & $\begin{array}{l}< \\
0.001\end{array}$ & $\begin{array}{l}1.15 \\
(1.08- \\
1.21)\end{array}$ \\
\hline$>10$ & 13373 & $\begin{array}{l}129.85 \pm \\
16.66^{\mathrm{cd}}\end{array}$ & & $\begin{array}{l}82.67 \pm \\
11.88 \mathrm{~cd}\end{array}$ & & 4615 & 34.51 & $\begin{array}{l}< \\
0.001\end{array}$ & $\begin{array}{l}1.20 \\
(1.13- \\
1.28)\end{array}$ \\
\hline
\end{tabular}

Smoking

status

\begin{tabular}{|c|c|c|c|c|c|c|c|c|c|}
\hline No & 28346 & $\begin{array}{l}125.45 \pm \\
15.76\end{array}$ & $\begin{array}{l}< \\
0.001^{a}\end{array}$ & $\begin{array}{l}78.70 \pm \\
11.40\end{array}$ & $\begin{array}{l}< \\
0.001^{a}\end{array}$ & 6154 & 21.71 & & $\begin{array}{l}1.00 \\
\text { (ref) }\end{array}$ \\
\hline Yes & 14242 & $\begin{array}{l}129.63 \pm \\
15.92\end{array}$ & & $\begin{array}{l}82.42 \pm \\
11.64\end{array}$ & & 4662 & 32.73 & $\begin{array}{l}< \\
0.001\end{array}$ & $\begin{array}{l}1.11 \\
(1.05- \\
1.17)\end{array}$ \\
\hline
\end{tabular}

Drinking

status

No

$28311 \quad 126.02 \pm$

$\begin{array}{ll}< & 79.27 \pm \\ 0.001 a & 11.54\end{array}$

$\begin{array}{lll}< & 6675 \quad 23.58 \\ 0.001^{a} & & \end{array}$

1.00

(ref) 
$S B P$, systolic blood pressure; $D B P$, diastolic blood pressure; $S D$, standard deviation; $O R$, odds ratio; $C l$, confidence interval

${ }^{a} t$-test of the difference between two groups

${ }^{\mathrm{b}}$ Kruskal-Wallis test of the difference between three groups

${ }^{c}$ Mann-Whitney test for a significant difference compared with the age $<35$ years and noise exposure time $<5$ years groups

d Mann-Whitney test for a significant difference compared with the age 35-44 years and noise exposure time 510 years groups

e Two-sided $\chi 2$ test for the frequency distributions of variables between groups

${ }^{f}$ Adjusted for gender, age, noise exposure time, smoking and drinking status in logistic regression model 
Table 3 Stratified analysis of binaural high frequency threshold on average and prevalence of NIHL by different variable groups

\begin{tabular}{|c|c|c|c|c|c|c|c|}
\hline \multirow[t]{2}{*}{ Variable } & \multirow[t]{2}{*}{$\mathrm{n}$} & $\begin{array}{l}\text { Binaural } \\
\text { high } \\
\text { frequency } \\
\text { threshold } \\
\text { on } \\
\text { average } \\
\text { (dB) }\end{array}$ & \multirow[t]{2}{*}{$P$} & Normal hearing & $\mathrm{NIHL}$ & \multirow[t]{2}{*}{$p^{e}$} & \multirow[t]{2}{*}{$\begin{array}{l}\text { Adjusted } \\
\text { OR }(95 \% \\
\text { Cl) }\end{array}$} \\
\hline & & $\begin{array}{l}\text { Mean } \pm \\
\text { SD }\end{array}$ & & $\%$ & $\mathrm{n}$ & & \\
\hline
\end{tabular}

\section{Gender}

\begin{tabular}{|c|c|c|c|c|c|c|c|c|c|}
\hline Female & 10750 & $\begin{array}{l}22.14 \pm \\
9.60\end{array}$ & $\begin{array}{l}< \\
0.001^{a}\end{array}$ & 8529 & 79.34 & 2221 & 20.66 & $\begin{array}{l}< \\
0.001\end{array}$ & $\begin{array}{l}1.00 \\
\text { (ref) }\end{array}$ \\
\hline Male & 31838 & $\begin{array}{l}23.41 \pm \\
11.83\end{array}$ & & 23676 & 74.36 & 8162 & 25.64 & & $\begin{array}{l}1.52 \\
(1.42 \\
1.62)\end{array}$ \\
\hline
\end{tabular}

Age

(years)

\begin{tabular}{|c|c|c|c|c|c|c|c|c|c|}
\hline$<35$ & 18865 & $\begin{array}{l}20.69 \pm \\
8.06\end{array}$ & 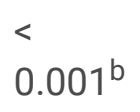 & 16271 & 86.25 & 2594 & 13.75 & & $\begin{array}{l}1.00 \\
\text { (ref) }\end{array}$ \\
\hline $35-44$ & 13363 & $\begin{array}{l}23.86 \pm \\
11.45^{c}\end{array}$ & & 9696 & 72.56 & 3667 & 27.44 & $\begin{array}{l}< \\
0.001\end{array}$ & $\begin{array}{l}1.93 \\
(1.81- \\
2.05)\end{array}$ \\
\hline$>44$ & 10360 & $\begin{array}{l}26.47 \pm \\
14.72^{\text {cd }}\end{array}$ & & 6238 & 60.21 & 4122 & 39.79 & $\begin{array}{l}< \\
0.001\end{array}$ & $\begin{array}{l}3.16 \\
(2.96- \\
3.38)\end{array}$ \\
\hline
\end{tabular}

Noise

exposure

time

(years)

\begin{tabular}{|c|c|c|c|c|c|c|c|c|c|}
\hline$<5$ & 16425 & $\begin{array}{l}20.46 \pm \\
7.67\end{array}$ & $\begin{array}{l}<.001^{b} \\
0\end{array}$ & 14673 & 89.33 & 1752 & 10.67 & & $\begin{array}{l}1.00 \\
\text { (ref) }\end{array}$ \\
\hline $5-10$ & 12790 & $\begin{array}{l}24.30 \pm \\
12.06^{c}\end{array}$ & & 8859 & 69.27 & 3931 & 30.73 & $\begin{array}{l}<.001 \\
0.00\end{array}$ & $\begin{array}{l}3.35 \\
(3.14- \\
3.57)\end{array}$ \\
\hline$>10$ & 13373 & $\begin{array}{l}25.16 \pm \\
13.51^{\mathrm{cd}}\end{array}$ & & 8673 & 64.85 & 4700 & 35.15 & $<.001$ & $\begin{array}{l}2.72 \\
(2.54- \\
2.91)\end{array}$ \\
\hline
\end{tabular}

\section{Smoking}

status

\begin{tabular}{|c|c|c|c|c|c|c|c|c|c|}
\hline No & 28346 & $\begin{array}{l}22.44 \pm \\
10.57\end{array}$ & $\begin{array}{l}< \\
0.001^{\mathrm{a}}\end{array}$ & 22252 & 78.50 & 6094 & 21.50 & & $\begin{array}{l}1.00 \\
\text { (ref) }\end{array}$ \\
\hline Yes & 14242 & $\begin{array}{l}24.38 \pm \\
12.58\end{array}$ & & 9953 & 69.88 & 4289 & 30.12 & $\begin{array}{l}< \\
0.001\end{array}$ & $\begin{array}{l}1.09 \\
(1.03- \\
1.16)\end{array}$ \\
\hline
\end{tabular}


Drinking

status

\begin{tabular}{|c|c|c|c|c|c|c|c|c|c|}
\hline No & 28311 & $\begin{array}{l}22.88 \pm \\
11.03\end{array}$ & $\begin{array}{l}< \\
0.001^{a}\end{array}$ & 21643 & 76.45 & 6668 & 23.55 & & $\begin{array}{l}1.00 \\
\text { (ref) }\end{array}$ \\
\hline Yes & 14277 & $\begin{array}{l}23.51 \pm \\
11.86\end{array}$ & & 10562 & 73.98 & 3715 & 26.02 & $\begin{array}{l}< \\
0.001\end{array}$ & $\begin{array}{l}0.95 \\
(0.90 \\
1.00)\end{array}$ \\
\hline
\end{tabular}

$d B$, decibel; $N I H L$, noise-induced hearing loss; $S D$, standard deviation; $O R$, odds ratio; $C l$, confidence interval

${ }^{a} t$-test of the difference between two groups

${ }^{\mathrm{b}}$ Kruskal-Wallis test of the difference between three groups

${ }^{c}$ Mann-Whitney test for a significant difference compared with the age $<35$ years and noise exposure time $<5$ years groups

${ }^{\mathrm{d}}$ Mann-Whitney test for a significant difference compared with the age 35-44 years and noise exposure time 510 years groups

e Two-sided $\chi 2$ test for the frequency distributions of variables between groups

${ }^{f}$ Adjusted for gender, age, noise exposure time, smoking and drinking status in logistic regression model

Table 4 Analysis of the association between NIHL and hypertension

\begin{tabular}{|c|c|c|c|c|c|c|}
\hline \multirow[t]{2}{*}{ Group } & \multirow[t]{2}{*}{$n$} & \multirow{2}{*}{$\begin{array}{l}\text { Resting SBP } \\
\text { Mean } \pm \text { SD (mm } \\
\text { Hg) }\end{array}$} & \multirow{2}{*}{$\begin{array}{l}\text { Resting DBP } \\
\text { Mean } \pm \text { SD (mm } \\
\text { Hg) }\end{array}$} & \multicolumn{2}{|c|}{ Hypertension } & \multirow{2}{*}{$\begin{array}{l}\text { Adjusted OR } \\
(95 \% \mathrm{CI})^{\mathrm{C}}\end{array}$} \\
\hline & & & & $\mathrm{n}$ & $\%$ & \\
\hline $\begin{array}{l}\text { Normal } \\
\text { hearing }\end{array}$ & 32205 & $125.82 \pm 15.48$ & $79.23 \pm 11.32$ & 7468 & 23.19 & 1.00 (ref) \\
\hline NIHL & 10383 & $130.03 \pm 16.89$ & $82.16 \pm 12.21$ & 3348 & 32.25 & $\begin{array}{l}1.08(1.03- \\
1.14)\end{array}$ \\
\hline$P$ & & $<0.001^{a}$ & $<0.001^{a}$ & \multicolumn{2}{|c|}{$<0.001^{b}$} & \\
\hline
\end{tabular}

$S B P$, systolic blood pressure; $D B P$, diastolic blood pressure; $S D$, standard deviation; $O R$, odds ratio; $C l$, confidence interval; $N I H L$, noise-induced hearing loss

a $t$-test of the difference between two groups

$\mathrm{b}$ Two-sided $\chi 2$ test for the frequency distributions of variables between two groups

${ }^{c}$ Adjusted for gender, age, noise exposure time, smoking and drinking status in logistic regression model

\section{Figures}



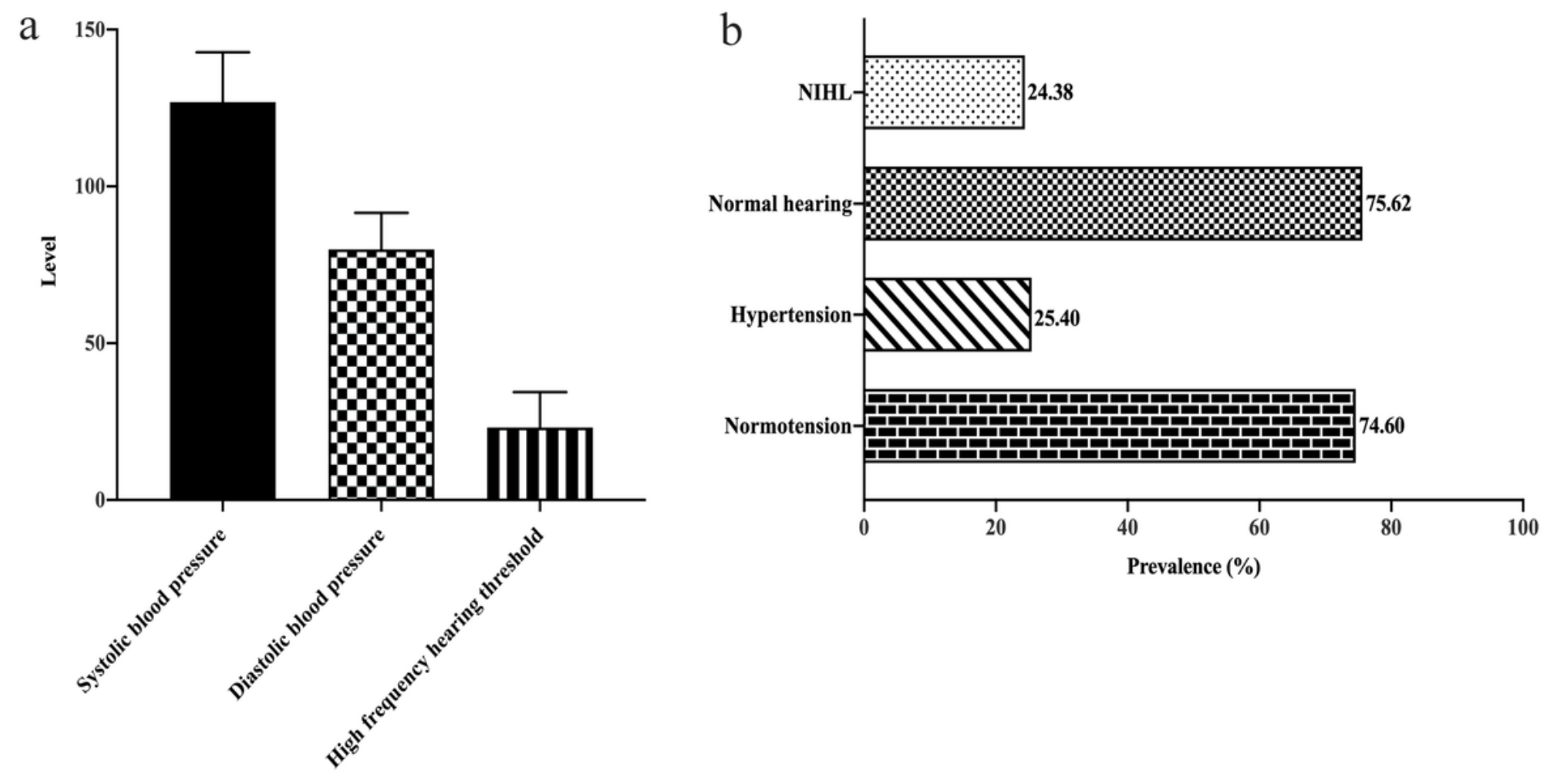

Figure 1

Overall mean levels of systolic blood pressure, diastolic blood pressure, and high frequency hearing thresholds, and prevalence of NIHL and hypertension among the included 42,588 participants. a The distribution of mean systolic blood pressure, diastolic blood pressure, and high frequency hearing thresholds. $b$ The distribution of prevalence of $\mathrm{NIHL}$ and hypertension. Data were presented as the mean \pm SD and percent 